\title{
One-step and high-density protein immobilization on epoxysilane-modified silica nanoparticles
}

\author{
ZHANG Qin, HUANG RongFu \& GUO Liang-Hong ${ }^{\dagger}$ \\ State Key Laboratory of Environmental Chemistry and Ecotoxicology, Research Center for Eco-environmental Sciences, Chinese \\ Academy of Sciences, Beijing 100085, China
}

Silica nanoparticles are most commonly modified with amino-silanes, followed by post-modification activation for protein immobilization. In this work, epoxy-functionalized silica nanoparticles were prepared by modification with glycidyloxypropyl trimethoxysilane (GPTMS) for direct protein immobilization. Silica nanoparticles possessed an average size of $46 \mathrm{~nm}$, but increased to $63 \mathrm{~nm}$ after GPTMS modification. Reaction time, reaction temperature and GPTMS content had no significant effect on particle size. Zeta potential of $\mathrm{SiO}_{2}$ changed from $-26 \mathrm{mV}$ to $+38 \mathrm{mV}$ after modification. Fourier-transformed infrared spectroscopy revealed alkyl $\mathrm{C}-\mathrm{H}$ bending and stretching bands at $2944 \mathrm{~cm}^{-1}, 1343 \mathrm{~cm}^{-1}$ and $1465 \mathrm{~cm}^{-1}$, respectively, for the modified nanoparticles. Fluorescein cadaverine was found to bind to GPTMS-modified $\mathrm{SiO}_{2}$, but not to bare $\mathrm{SiO}_{2}$, indicating the chemical reactivity of epoxy groups on the modified nanoparticle with amines. Finally, fluorescently labeled bovine serum albumin (BSA) was used as a model protein to investigate the capacity of epoxy- $\mathrm{SiO}_{2}$ nanoparticles for protein immobilization. The results showed that more proteins were immobilized on the particle with longer reaction time, higher $\mathrm{NaCl}$ concentration, lower $\mathrm{pH}$, and less GPTMS content. More importantly, proteins bound to epoxy- $\mathrm{SiO}_{2}$ nanoparticle were highly stable. Under optimized reaction conditions, as much as $25 \mathrm{mg}$ BSA/g nanoparticle was covalently attached to the nanoparticle. The epoxy silane modification of silica nanoparticles offers a reactive surface for one-step and high-density protein immobilization.

epoxysilane, silica nanoparticle, protein immobilization

In the past few years, nanomaterials of various shapes (particles, wires, rods, tubes, etc.) have been synthesized and characterized. They have been found to possess unique size-dependent properties in terms of quantum effect, specific surface area, electric conductivity, mechanical strength, and catalytic reactivity ${ }^{[1]}$. Consequently, nanomaterials have been found wide applications in the field of biological analysis and detection, biological imaging and drug delivery ${ }^{[2,3]}$. Among them, silica nanoparticles have been studied extensively due to their easy synthesis, readily available surface modification, good dispersibility and stability in water, and biocompatibility $^{[4]}$. Mesoporous silica nanoparticles can be employed as drug delivery vehicles for controlled release $^{[5]}$. Surface-coated silica nanoparticles act as a carrier for multiple optical ${ }^{[6,7]}$ and electrochemical ${ }^{[8]}$ labels to enhance detection signal. Dye-doped silica nanoparticles are more resistant to photo-bleaching than fluorescent dye molecules and much less toxic than quantum dots. They therefore offer distinct advantages when applied to in vivo fluorescence imaging ${ }^{[9,10]}$. Ruthenium tris(bipyridyl)-doped silica nanoparticles ${ }^{[11-13]}$ have been used as electrochemiluminescent labels to provide large quantities of $\mathrm{Ru}(\mathrm{bpy})_{3}{ }^{2+}$ molecules for signal detection. Furthermore, silica coating on other

Received December 10, 2008; accepted February, 18, 2009 doi: 10.1007/s11434-009-0210-7

†Corresponding author (email: 1hguo@rcees.ac.cn)

Supported by the National Basic Research Program of China (Grant No. 2006CB403303) and the National Natural Science Foundation of China (Grant Nos. 20621703, and 20825519) 
nanoparticle materials (core-shell structure) allows these materials to retain the desired magnetic or optical properties. In the mean time, the silica shell makes them more biocompatible and easier to be functionalized $^{[14-16]}$.

For biomolecule immobilization, silica nanoparticles need to be functionalized by surface modification to present reactive groups to biomolecules. To date, the most commonly employed method for surface modification of silica nanoparticles is silanization. Aminosilanes are coupled to the silica surface, and the terminal amino group is activated by reacting with glutaraldehyde. Proteins or amino-modified DNAs can then be immobilized irreversibly on the activated particles via the covalent bond between the amino group on the biomolecule and the aldehyde ${ }^{[17-19]}$. Alternatively, the aminosilane surface can be transformed into carboxylic acid by reacting with succinic anhydride, followed by NHS/EDC activation $^{[20,21]}$. However, both procedures require a post-modification activation step before biomolecule immobilization, which adds considerable time and complexity. In addition, glutaraldehyde content and reaction sequence need to be controlled carefully in order to minimize nanoparticle crosslinking and aggregation.

Epoxysilane agents are classical compounds applied widely to a variety of polymer composite materials to enhance the stability and integrity of polymer/inorganic interfaces ${ }^{[22,23]}$. Epoxy activated surfaces are also very attractive systems for covalent biomolecule immobilization. Epoxy is reactive under mild experimental conditions toward many nucleophiles on proteins including amine, hydroxyl and thiol groups. The chemical bond thus formed is very stable. Epoxy-activated surface is also stable under normal storage conditions. Therefore, epoxysilane modification provides a chemically reactive surface for covalent protein immobilization without additional activation. Unfortunately, although epoxysilanes have been used extensively for the modification and activation of glass slides, glass beads and other silica materials, to our knowledge, there has been no report on the use of epoxysilane on silica nanoparticles.

The goal of the present work was to exploit epoxysilane chemistry as a convenient and one-step method for the activation of silica nanoparticles and protein immobilization. Epoxysilane-modified silica nanoparticles were fully characterized. Experimental conditions for surface modification and protein immobilization were investigated and optimized. It was found that as much as
$25 \mathrm{mg}$ bovine serum albumin was immobilized on $1 \mathrm{~g}$ activated nanoparticle with high stability.

\section{Experimental procedure}

\subsection{Chemicals}

Fluorescein cadaverine was purchased from Invitrogen (Carlsbad, CA). Fluorescein isothiocyanate (FITC) was purchased from Amresco (Solon, OH), Biotinyl-N-hydroxy-succinimide (BT-NHS), Triton X-100 and glycidyloxypropyl trimethoxysilane (GPTMS) were from Sigma Aldrich (St. Louis, MO). Bovine serum albumin fraction $\mathrm{V}$ (BSA), mouse $\mathrm{IgG}$ and goat anti-mouse IgG were from Xinjingke Corp (Beijing, China). Tetraethyl orthosilicate (TEOS) was from Beijing Chemical Reagent Corp. (Beijing, China). Other reagents are all of analytic purity. All buffers were prepared in high-purity water from a Millipore Milli-Q (Biocel) purification system.

FITC labeled BSA (FITC-BSA) was obtained by mixing BSA with FITC at a molar ratio of 10 FITC: 1 BSA in $0.1 \mathrm{~mol} / \mathrm{L}$ sodium bicarbonate $(\mathrm{pH} \mathrm{9.15)} \mathrm{for} 4 \mathrm{~h}$ at room temperature with stirring. After the reaction, the remaining free FITC was separated from the antibody by gel filtration on a D-Salt ${ }^{\mathrm{TM}}$ polyacrylamide desalting column from Pierce (Rockford, IL). The protein and FITC concentration of the labeled BSA were determined by absorbance at $280 \mathrm{~nm}$ and $495 \mathrm{~nm}$ respectively on a UNICO UV-2800 spectrophotometer (Shanghai, China). And the labeling ratio was determined to be 2 FITC per BSA. Biotinylated goat anti-mouse antibody (BT-Ab) was obtained according to the previously described method $^{[24]}$. The labeling ratio was 1.9 biotins per antibody. The labeled proteins were stored at $4^{\circ} \mathrm{C}$ in dark till use.

\subsection{Preparation of various $\mathrm{SiO}_{2}$ nanoparticles}

Bare $\mathrm{SiO}_{2}$ nanoparticles were prepared via modified reverse micro-emulsion method $^{[25]}$. In brief, $15 \mathrm{~mL}$ cyclohexane, $3.6 \mathrm{~mL} n$-hexanol, $4 \mathrm{~mL}$ Triton X-100, and $1 \mathrm{~mL}$ deionized $\mathrm{H}_{2} \mathrm{O}$ were mixed. Then $150 \mu \mathrm{L}$ TEOS and $100 \mu \mathrm{L}$ ammonia hydroxide were dropped into the micro-emulsion to react under stirring for $24 \mathrm{~h}$ at room temperature. The reaction mixture was added into acetone to break the micro-emulsion. Pellets were obtained by centrifugation at $12000 \mathrm{rpm}$ for $30 \mathrm{~min}$ at $4^{\circ} \mathrm{C}$. Supernatant was discarded and pellets were washed with water and ethanol by centrifugation. The particles 
were freeze dried in vacuum and stored at $4{ }^{\circ} \mathrm{C}$.

In the optimized procedure for silica nanoparticle modification, the nanoparticle prepared above was re-dispersed in dry toluene by sonication for $1 \mathrm{~h}$. Then $1 \%(\mathrm{~V} / \mathrm{V})$ GPTMS was added into the nanoparticle solution. After reaction with shaking for different time (from $1 \mathrm{~h}$ to $24 \mathrm{~h}$ ) and at different temperatures $\left(20^{\circ} \mathrm{C}\right.$, $37^{\circ} \mathrm{C}$ and $65^{\circ} \mathrm{C}$ ), nanoparticles modified with epoxy groups were obtained after $12,000 \mathrm{rpm}$ centrifuging for $30 \mathrm{~min}$ at $4^{\circ} \mathrm{C}$. The pellets were washed sequentially with dry toluene, acetone and ethanol, then freeze dried in vacuum, and stored at $4^{\circ} \mathrm{C}$.

Fluorescein cadaverine ( $\mathrm{NH}_{2}$-Fluo), a bifunctional chemical containing an amino group and a fluorescein, was reacted with epoxy $\mathrm{SiO}_{2}$ to produce dye-coated nanoparticles. In the reaction, $0.5 \mathrm{mg}$ epoxy nanoparticles and $649 \mu \mathrm{mol} / \mathrm{L} \mathrm{NH}_{2}$-Fluo dissolved in phosphate buffer (138 mmol/L NaCl, $2.7 \mathrm{mmol} / \mathrm{L} \mathrm{KCl}, 8.1 \mathrm{mmol} / \mathrm{L}$ $\mathrm{Na}_{2} \mathrm{HPO}_{4}, 1.1 \mathrm{mmol} / \mathrm{L} \mathrm{KH} \mathrm{KO}_{4}, \mathrm{pH} 7.0, \mathrm{PBS}$ ) were incubated at $37^{\circ} \mathrm{C}, 240 \mathrm{rpm}$ with shaking for $16 \mathrm{~h}$. After incubation, nanoparticles were washed with washing buffer (PBS buffer with 2\% Tween 20, PBST) and centrifuged at $4^{\circ} \mathrm{C}, 12,000 \mathrm{rpm}$, for $25 \mathrm{~min}$. After washing for three times, the nanoparticles were resuspended in $0.1 \mathrm{~mol} / \mathrm{L} \mathrm{PB}$ buffer $\left(0.1 \mathrm{~mol} / \mathrm{L} \mathrm{Na}_{2} \mathrm{HPO}_{4}, 0.1 \mathrm{~mol} / \mathrm{L}\right.$ $\mathrm{KH}_{2} \mathrm{PO}_{4}, \mathrm{pH} 8.0, \mathrm{~PB}$ ) and fluorescence intensity was measured on an LS55 luminescence spectrometer (Perkin Elmer, USA)excitation $498 \mathrm{~nm}$, slit $5 \mathrm{~nm}$, emission $525 \mathrm{~nm}$, slit $5 \mathrm{~nm}$, scan rate $600 \mathrm{~nm} / \mathrm{s}$ ).

In the optimized procedure for protein immobilization on epoxy-modified silica nanoparticles, $0.2 \mathrm{mg}$ epoxy- $\mathrm{SiO}_{2}$ and $3.4 \mathrm{mg} / \mathrm{mL}$ FITC-BSA dissolved in phosphate buffer containing different concentrations of $\mathrm{NaCl}$ were incubated for $24 \mathrm{~h}$ at $37^{\circ} \mathrm{C}, 240 \mathrm{rpm}$ with shaking. After incubation, the nanoparticles were washed with PBST buffer and centrifuged at $4^{\circ} \mathrm{C}, 12,000 \mathrm{rpm}$ for 25 $\mathrm{min}$. The nanoparticles were resuspended in $0.1 \mathrm{~mol} / \mathrm{L}$ PB buffer and fluorescence intensity was measured (excitation $494 \mathrm{~nm}$, slit $5 \mathrm{~nm}$, emission $525 \mathrm{~nm}$, slit $5 \mathrm{~nm}$, scan rate $600 \mathrm{~nm} / \mathrm{s}$ ).

\subsection{Characterization of silica nanoparticles}

Unmodified or epoxysilane-modified $\mathrm{SiO}_{2}$ nanoparticles were re-dispersed in ethanol by sonication for $1 \mathrm{~h}$. The particles were detected by transmission electron microscopy (TEM) (H-7500, Hitachi, Japan) for particle size and morphology.

For zeta potential measurement, the nanoparticles were re-suspended in pure water after $1 \mathrm{~h}$ sonication. The supernatants were injected into a Zetasizer 2000 zeta potential detector (Malvern Co., United Kingdom).

Fourier transformed infrared (FT-IR) spectra were measured on a Vector 22 FT-IR spectrometer (Brucker, Germany) using a $\mathrm{KBr}$ disc for sample preparation. Sixteen scans were collected at a resolution of $4 \mathrm{~cm}^{-1}$.

\section{Results and discussion}

\subsection{Epoxysilane modification of silica nanoparticles}

It is well known that, compared with Stöber method ${ }^{[26]}$, silica nanoparticles prepared by the reverse micro-emulsion method have smaller size and better homogeneity. Therefore, reverse micro-emulsion method was employed in our work to synthesize $\mathrm{SiO}_{2}$ nanoparticles, using a water-to-surfactant molar ratio (W/O value) of 8.15. TEM graph in Figure 1(a) shows that the synthesized nanoparticles were spherical in shape and uniform in size, with an average diameter of $46.2 \pm$ $5.7 \mathrm{~nm}$.

The surface of the particles was functionalized with epoxy groups by reacting with GPTMS for protein immobilization. As depicted in Figure 1(b), after only 1 $h$ reaction, particle size increased significantly to $63.1 \pm 4.5 \mathrm{~nm}$. But the shape remained spherical. Since the thickness of a GPTMS monolayer is reported to be $0.8 \mathrm{~nm}^{[27]}$, it can be inferred from the $17 \mathrm{~nm}$ increase in particle size that an equivalent of about 20 layers of GPTMS was formed on the surface of silica nanoparticles. Higher GPTMS concentration (5\% and 10\%) and longer reaction time up to $24 \mathrm{~h}$ did not increase the particle size any further (Figure 1(c)), suggesting that the surface silanization reaction was complete within 1h even with only $1 \%$ GPTMS. Three different reaction temperatures, $20^{\circ} \mathrm{C}, 37^{\circ} \mathrm{C}$ and $65^{\circ} \mathrm{C}$, were investigated. Although average particle size did not change with the temperature, size distribution was slightly more uniform for particles produced at $65^{\circ} \mathrm{C}$. Therefore, in the optimized procedure for silica nanoparticle modification, $1 \%(\mathrm{v} / \mathrm{v})$ GPTMS was reacted with the particle at $65^{\circ} \mathrm{C}$ for $1 \mathrm{~h}$.

Zeta potential is a function of surface charge, and is very sensitive to the chemical groups on the surface of a solid material. The zeta potential of both bare and modified silica nanoparticles was measured. Bare $\mathrm{SiO}_{2}$ was found 

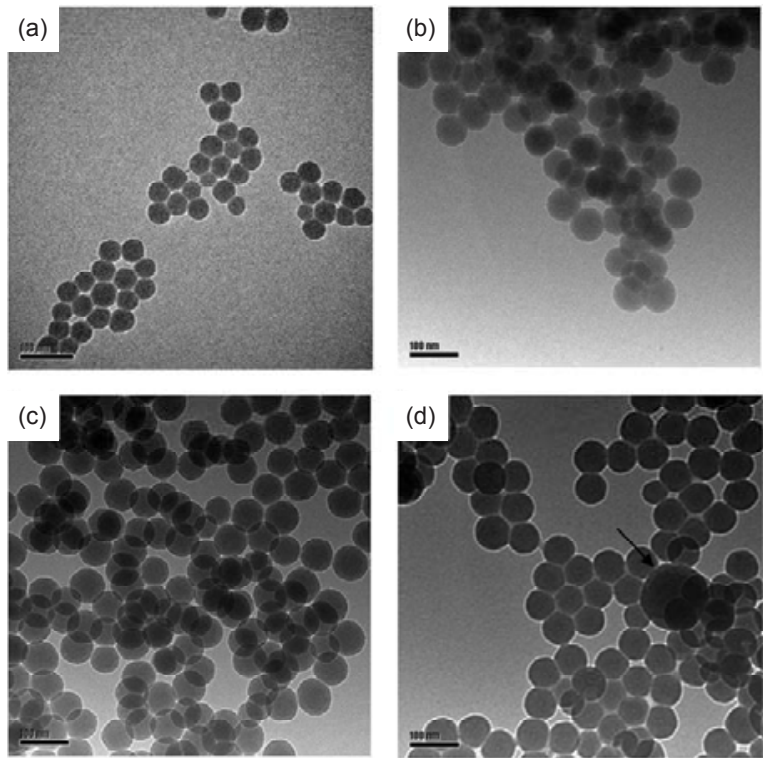

Figure 1 TEM graphs of (a) bare $\mathrm{SiO}_{2}$ nanoparticles; (b) epoxy-modified $\mathrm{SiO}_{2}$ after $1 \mathrm{~h}$ reaction at $20^{\circ} \mathrm{C}$; (c) epoxy-modified $\mathrm{SiO}_{2}$ after $24 \mathrm{~h}$ reaction at $20^{\circ} \mathrm{C}$; (d) epoxy-modified $\mathrm{SiO}_{2}$ after $1 \mathrm{~h}$ reaction at $65^{\circ} \mathrm{C}$. GPTMS concentration was $1 \%(\mathrm{v} / \mathrm{v})$. Scale bar was $100 \mathrm{~nm}$.

to have a potential of $-26.27 \pm 0.71 \mathrm{mV}$ in pure water (pH 6.8), due to the negative charge of hydroxyl groups on the particle surface. The potential is similar to the values reported in other publications ${ }^{[28,29]}$. After epoxysilane reaction, the nanoparticles turned into positive charge $(+38.07 \pm 0.55 \mathrm{mV})$, indicating conversion of hydroxyl groups into other chemical functionalities.

The silica nanoparticles were characterized further by FT-IR. Figure 2 shows the FT-IR spectra of bare nanoparticles and the nanoparticles reacted with
GPTMS of different concentrations. Although the characteristic band of epoxy group at around $1150 \mathrm{~cm}^{-1}$ overlapped with strong absorption of the bare silica, alkyl C-H stretching vibration band at $2944 \mathrm{~cm}^{-1}$ and its bending vibration bands at $1343 \mathrm{~cm}^{-1}$ and $1465 \mathrm{~cm}^{-1[30-34]}$ were clearly visible in the spectra of the modified particle. The results indicate that epoxysilane was attached successfully to the surface of the silica nanoparticles. To investigate the chemical reactivity of the epoxy groups on the epoxysilane-modified silica nanoparticles, fluorescein cadaverine reacted with the nanoparticles. The fluorescent dye contains an amino group, and can be immobilized on the nanoparticle by forming a covalent bond with the epoxy group. As shown in Figure 3, after reacting with $\mathrm{NH}_{2}$-Fluo, fluorescence intensity of bare silica nanoparticles was only slightly higher than the background. The slight increase is most likely due to some non-specifically bound dyes on the particle. By contrast, GPTMS-modified nanoparticles emitted approximately 20 -fold more fluorescence after dye attachment. The results demonstrate that the epoxy functionalities on the modified $\mathrm{SiO}_{2}$ nanoparticle were reactive toward amine groups, and could be used directly (without activation) for covalent protein immobilization, as described below.

\subsection{Protein immobilization on epoxysilane-modifi ed} silica nanoparticles

Most proteins contain lysine residues which react readily with epoxy groups through the primary amine of the

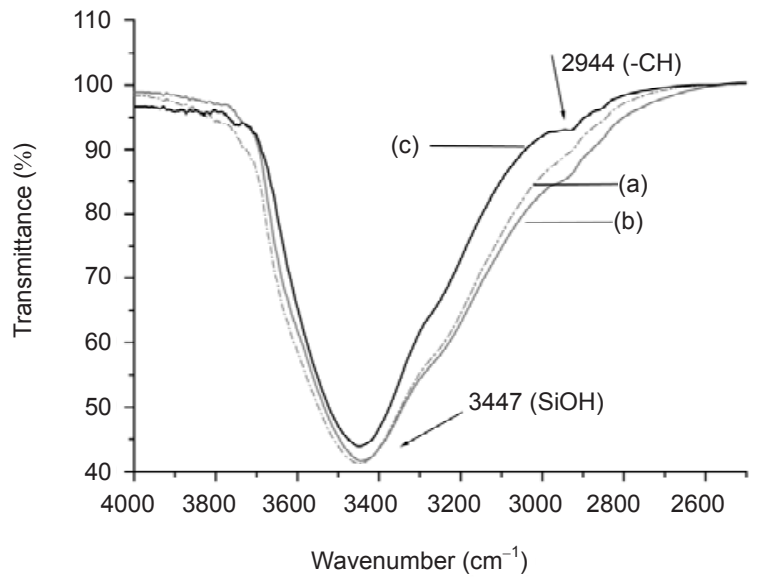

Wavenumber $\left(\mathrm{cm}^{-1}\right)$

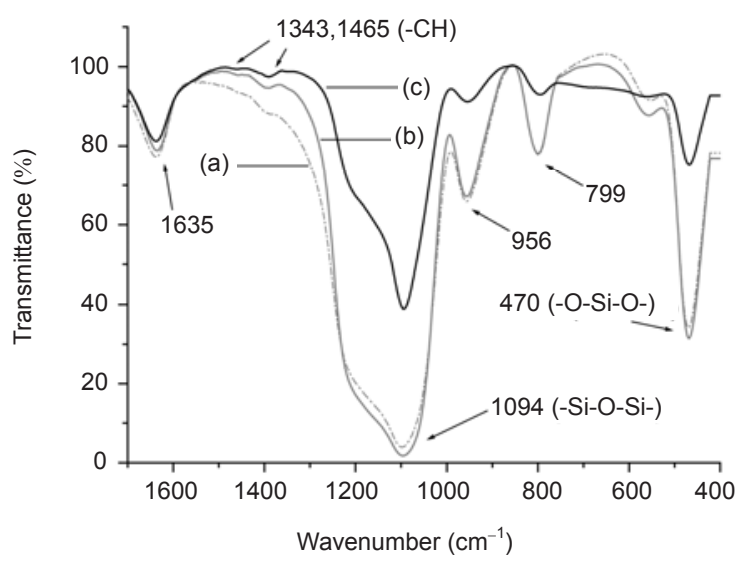

Figure 2 FT-IR spectra of (a) bare silica nanoparticles; (b) silica nanoparticles reacted with $1 \%$ GPTMS; (c) silica nanoparticles reacted with $10 \%$ GPTMS. The scale of wavenumber of graph is from $1700 \mathrm{~cm}^{-1}$ to $400 \mathrm{~cm}^{-1}$ (left) and from $2500 \mathrm{~cm}^{-1}$ to $4000 \mathrm{~cm}^{-1}$ (right), respectively. 


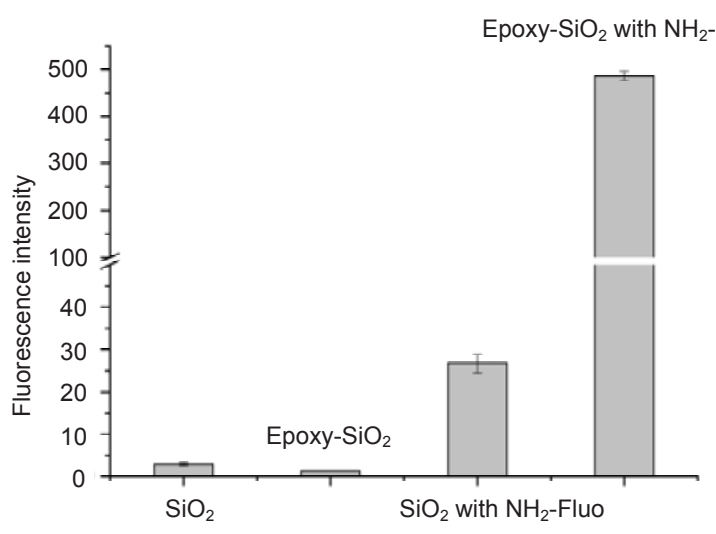

Figure 3 Fluorescence intensity of various $\mathrm{SiO}_{2}$ nanoparticles dispersed in $0.1 \mathrm{~mol} / \mathrm{L} \mathrm{PB}$ buffer. Excitation at $498 \mathrm{~nm}$, emission at $525 \mathrm{~nm}$. Error bar represents standard deviation $(n=3)$.

amino acid. In our work, BSA was employed as a model protein to investigate protein immobilization on epoxy-functionalized silica nanoparticles. The protein was labeled with a fluorescent dye, FITC, for protein quantification on the particle. To immobilize FITCBSA, the protein was incubated with GPTMS-modified nanoparticle for a specified time. The particle was then washed, and re-suspended in a phosphate buffer for fluorescence measurement. Figure 4 shows that the fluorescence intensity of FITC-BSA-immobilized silica nanoparticle increased steadily with incubation time. The signal did not reach a plateau even after $24 \mathrm{~h}$ incubation, suggesting a slow reaction rate for protein immobilization.

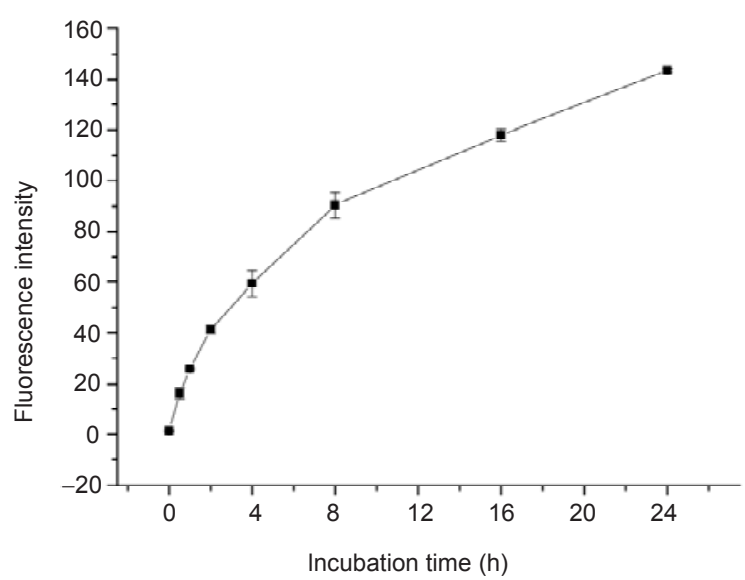

Figure 4 Fluorescence intensity of FITC-BSA-immobilized epoxy-SiO $\mathrm{S}_{2}$ nanoparticle as a function of protein incubation time. Incubation was carried out in PBS buffer. Fluorescence was measured by dispersing the particles in $0.1 \mathrm{~mol} / \mathrm{L} \mathrm{PB}$ buffer. Excitation is at $494 \mathrm{~nm}$, and emission at $525 \mathrm{~nm}$. Error bar represents standard deviation $(n=3)$.
It was found that salt had some dramatic impact on BSA immobilization on the epoxy nanoparticle. Figure 5 shows that as $\mathrm{NaCl}$ was added into the reaction buffer, the amount of BSA immobilized on the nanoparticle increased significantly. At the highest concentration investigated $(1 \mathrm{~mol} / \mathrm{L} \mathrm{NaCl})$, fluorescence signal increased almost 5-fold. It is well known epoxy groups are stable and not very reactive under mild experimental conditions. However, it has also been found that high concentrations of salt facilitate protein immobilization on epoxy-functionalized chromatographic supports ${ }^{[35,36]}$. In the hypothesized mechanism, hydrophobic interactions are enhanced in the presence of high-concentration salt. Proteins are first adsorbed hydrophobically on the surface, followed by the formation of covalent bonds between nucleophiles of the protein and the epoxy groups on the surface. The salt effect observed in our experiment with epoxy-modified nanoparticles can also be interpreted by the same mechanism.

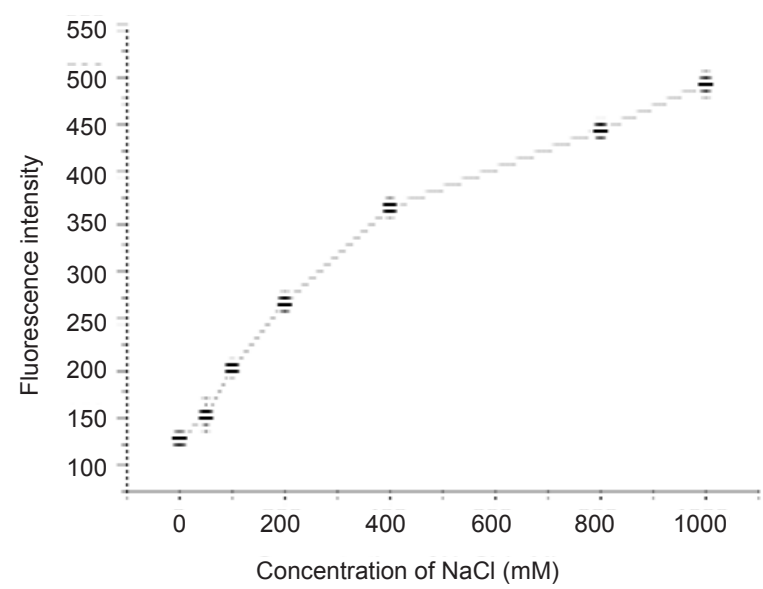

Figure 5 Fluorescence intensity of FITC-BSA-immobilized epoxy- $\mathrm{SiO}_{2}$ nanoparticle as a function of $\mathrm{NaCl}$ concentration in protein immobilization buffer. FITC-BSA was dissolved in $10 \mathrm{mmol} / \mathrm{L}$ phosphate buffer ( $\mathrm{pH}$ 7.0) containing different concentrations of $\mathrm{NaCl}$. Fluorescence was measured by dispersing the particles in $0.1 \mathrm{~mol} / \mathrm{L}$ PB buffer. Excitation is at $494 \mathrm{~nm}$, and emission at 525 $\mathrm{nm}$. Error bar represents standard deviation $(n=3)$.

In the optimized procedure for protein immobilization, epoxy-modified silica nanoparticles were incubated with BSA in $10 \mathrm{mmol} / \mathrm{L}$ phosphate buffer with $1 \mathrm{~mol} / \mathrm{L} \mathrm{NaCl}$ $(\mathrm{pH} 7.0)$ at $37^{\circ} \mathrm{C}$ for $24 \mathrm{~h}$. Under these experimental conditions, the amount of immobilized BSA correlated very well with its solution concentration until the concentration reached $3.4 \mathrm{mg} / \mathrm{mL}$, as depicted in Figure 6 . On bare silica nanoparticles, some FITC-BSA proteins were adsorbed non-specifically on the surface. The weakly 


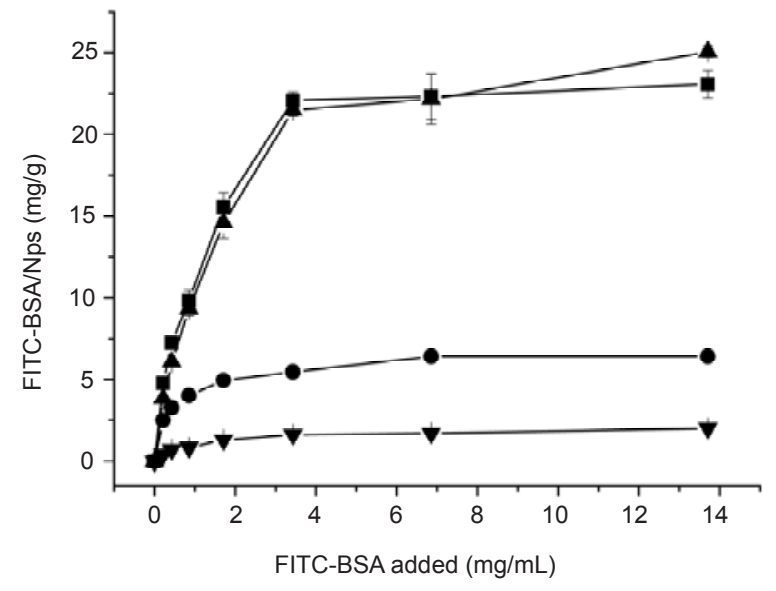

Figure 6 Amount of FITC-BSA immobilized on various silica nanoparticles as a function of protein concentration. The nanoparticles are bare $\mathrm{SiO}_{2}$ (circle), bare $\mathrm{SiO}_{2}$ washed with $\mathrm{BSA}$ (inverse triangle), epoxy $\mathrm{SiO}_{2}$ (square), and epoxy $\mathrm{SiO}_{2}$ washed with $\mathrm{BSA}$ (triangle).

bound proteins could be removed by washing in a BSA-containing buffer. By contrast, the proteins immobilized on the epoxy-functionalized nanoparticles were very stable, and could not be washed off with the same buffer. The strong binding reflects the covalent nature of the interaction between BSA and surface. At high protein

1 Gleiter H. Deformation of polycrystals: Mechanism and Microstructures. Roskilde: Riso Nat. Lab. 1981, 15.

2 Patolsky F, Zheng G, Lieber C M. Nanowire sensors for medicine and the life sciences. Nanomedicine-UK, 2006, 1: 51-56.

3 Liu Y Y, Miyoshi H, Nakamura M. Nanomedicine for drug delivery and imaging: A promising avenue for cancer therapy and diagnosis using targeted functional nanoparticles. Int J Cancer, 2007, 120: 2527-2537.

4 Tallury P, Payton K, Santra S. Silica-based multimodal/multifunctional nanoparticles for bioimaging and biosensing applications. Nanomedicine-UK, 2008, 3: 579-592.

5 Liang X J, Chen C Y, Zhao Y L, et al. Biopharmaceutics and therapeutic potential of engineered nanomaterials. Curr Drug Metab, 2008, 9: $697-709$.

6 Xu Y, Li Q G. Multiple fluorescent labeling of silica nanoparticles with lanthanide chelates for highly sensitive time-resolved Immunofluorometric assays. Clin Chem, 2007, 53: 1503-1510.

7 Gao D M, Wang, Z Y, Liu, B H, et al. Resonance energy transfer-amplifying fluorescence quenching at the surface of silica nanoparticles toward ultrasensitive detection of TNT. Anal Chem, 2008, 80: 8545-8553.

8 Liu G D, Lin Y H. Nanomaterial labels in electrochemical immunosensors and immunoassays. Talanta, 2007, 74: 308-317.

9 Hun X, Zhang Z J. Fluoroimmunoassay for tumor necrosis factoralpha in human serum using $\mathrm{Ru}(\text { bpy })_{3} \mathrm{Cl}_{2}$-doped fluorescent silica nanoparticles as labels. Talanta, 2007, 73: 366-371. concentrations, as much as $25 \mathrm{mg}$ BSA was immobilized on $1 \mathrm{~g}$ nanoparticles.

\section{Conclusion}

In this study, silica nanoparticles were functionalized with epoxysilane for direct protein immobilization. Silica nanoparticles prepared by reverse micro-emulsion were examined by TEM for particle size and size distribution. Zeta potential and FT-IR were employed to verify the modification of the nanoparticles. Chemical reactivity of the epoxy group on the modified particle was confirmed by its reaction with an amine-containing fluorescent dye. Fluorescently labeled BSA was used as a model protein to investigate experimental conditions for protein immobilization on the modified nanoparticles. Under the optimized reaction conditions, as much as $25 \mathrm{mg} \mathrm{BSA} / \mathrm{g}$ nanoparticle was immobilized on the nanoparticle with high stability. The epoxy-functionalized silica nanoparticles are very stable under normal storage conditions, and are reactive toward many nucleophilic groups present in most proteins. They therefore offer an attractive material for one-step and high-density protein immobilization.

10 Yan J L, Estevez M C, Tan W H, et al. Dye-doped nanoparticles for bioanalysis. Nano Today, 2007, 2: 44-50.

11 Chang Z, Zhou J M, Zhao K, et al. Ru(bpy) ${ }_{3}{ }^{2+}$-doped silica nanoparticle DNA probe for the electrogenerated chemiluminescence detection of DNA hybridization. Electrochim Acta, 2006, 52: 575-580.

12 Wei H, Wang E. Electrochemiluminescence-based DNA detection using guanine oxidation at electrostatic self-assembly of $\mathrm{Ru}(\mathrm{bpy})_{3}{ }^{2+}$-doped silica nanoparticles on indium tin oxide electrode. Chem Lett, 2007, 36: 210-211.

13 Wang X Y, Yun W, Zhou J M, et al. Ru(bpy) ${ }_{3}{ }^{2+}$-doped silica nanoparticle aptasensor for detection of thrombin based on electrogenerated chemiluminescence. Chinese J Chem, 2008, 26: 315320 .

14 Burns A, Ow H, Wiesner U. Fluorescent core-shell silica nanoparticles: towards "Lab on a Particle" architectures for nanobiotechnology. Chem Soc Rev, 2006, 35: 1028-1042.

15 Lu H C, Yi G S, Zhao S Y, et al. Synthesis and characterization of multi-functional nanoparticles possessing magnetic, up-conversion fluorescence and bio-affinity properties. J Mater Chem, 2004, 14: $1336-1341$.

16 Liu W, Zhong W, Du Y W. Magnetic nanoparticles with core/shell structures. J Nanosci Nanotech, 2008, 8: 2781-2792.

17 Nobs L, Buchegger F, Gurny R, Allemann E. Current methods for attaching targeting ligands to liposomes and nanoparticles. J Pharm Sci-US, 2004, 93: 1980-1992. 
18 Vandenberg E, Elwing H, Askendal A, et al. Protein immobilization to 3-aminopropyl triethoxy silane/glutaradehyde surface: characterization by detergent washing. J Colloid Interf Sci, 1991, 143: $327-335$

19 Howarter J A, Youngblood J P. Optimization of silica silanization by 3-aminopropyltriethoxysilane. Langmuir, 2006, 22: 11142- 11147.

20 Liu S, Zhang H L, Liu T C, et al. Optimization of the methods for introduction of amine groups onto the silica nanoparticle surface. J Biomed Mater Res A, 2006, 80A: 752-757.

21 An Y Q, Chen M, Xue Q J, et al. Preparation and self-assembly of carboxylic acid-functionalized silica. J Colloid Interf Sci, 2007, 311: $507-513$

22 Plueddemann E P. Silane Coupling Agents. 2nd Edition. New York : Plenum Press, 1991, p118.

23 Shi D L. Introduction to Biomaterials. 1st Edition. 13. Polymer Matrix Composite Biomaterials. New Jersey: World Scientific Publishing Co, 2006, p198.

24 Zhang Q, Guo L H. Multiple labeling of antibodies with dye/DNA conjugate for sensitivity improvement in fluorescence immunoassay. Bioconjugate Chem, 2007, 18: 1668-1672.

25 Qhobosheane M, Santra S, Zhang P, et al. Biochemically functionalized silica nanoparticles. Analyst, 2001, 126: 1274-1278.

26 Bagwe R P, Yang C Y, Hilliard L R, et al. Optimization of dye-doped silica nanoparticles prepared using a reverse microemulsion method. Langmuir, 2004, 20: 8336-8342.

27 Luzinov I, Julthongpiput D, Liebmann-Vinson A, et al. Epoxy-terminated self-assembled monolayers: molecular glues for polymer layers. Langmuir, 2000, 16: 504-516.

28 Fisher M L, Colic M, Rao M P, et al. Effect of silica nanoparticle size on the stability of alumina/silica suspensions. J Am Ceram Soc, 2001, 84: 713-718.

29 Lee D, Gemici Z, Rubner M F, et al. Multilayers of oppositely charged $\mathrm{SiO}_{2}$ nanoparticles: effect of surface charge on multilayer assembly. Langmuir, 2007, 23: 8833-8837.

30 Tarducci C, Kinmond E J, Badyal J P S. Epoxide-functionalized solid surfaces. Chem Mater, 2000, 12: 1884-1889.

31 Schottner G. Hybrid sol-gel-derived polymers: applications of multifunctional materials. Chem Mater, 2001, 13: 3422-3435.

32 Alonso B, Massiot D, Babonneau F, et al. Structure control in germania hybrid organic-inorganic materials. Chem Mater, 2005, 17: $3172-3180$

33 Wanunu M, Livne S, Vaskevich A, et al. Assembly of coordination nanostructures via ligand derivatization of oxide surfaces. Langmuir, 2006, 22: 2130-2135.

34 Chen W F, Kuo P L. Covalently cross-linked perfluorosulfonated membranes with polysiloxane framework. Macromolecules, 2007, 40: $1987-1994$.

35 Wheatley J B, Schmidt D E. Salt induced immobilization of proteins on a high-performance liquid chromatographic epoxide affinity support. J Chromatogr A, 1993, 644: 11-16.

36 Wheatley J B, Schmidt D E. Salt induced immobilization of affinity ligands onto epoxide-activated supports. J Chromatogr A, 1999, 849: $1-12$. 